\title{
Raised intracranial pressure in Crouzon syndrome: incidence, causes, and management
}

\author{
Ghassan S. Abu-Sittah, MBChB, FRCS(Plast),, Owase Jeelani, FRCS(Eng), ${ }^{2}$ \\ David Dunaway, FRCS(Eng), ${ }^{1}$ and Richard Hayward, FRCS(Eng) ${ }^{2}$
}

Departments of ${ }^{1}$ Craniofacial Surgery and ${ }^{2}$ Neurosurgery, Great Ormond Street Hospital for Children NHS Foundation Trust, London, United Kingdom

OBJECTIVE Patients with Crouzon syndrome (CS) are at risk for developing raised intracranial pressure (ICP), which has the potential to impair both vision and neurocognitive development. For this reason, some experts recommend early prophylactic cranial vault expansion on the basis that if ICP is not currently raised, it is likely to become so. The aim of this study was to examine the justification for such a policy. This was done by analyzing the incidence, causes, and subsequent risk of recurrence in a series of patients with CS, in whom raised ICP was treated only after it had been diagnosed.

METHODS This study was a retrospective review of the medical records and imaging data of patients with a clinical diagnosis of CS.

RESULTS There were 49 patients in the study, of whom 30 (61.2\%) developed at least 1 episode of raised ICP. First episodes occurred at an average age of 1.42 years and were attributable to craniocerebral disproportion/venous hypertension (19 patients), hydrocephalus (8 patients), and airway obstruction (3 patients). They were managed, respectively, by vault expansion, ventriculoperitoneal shunt insertion, and airway improvement. Fourteen of the 30 patients developed a second episode of raised ICP an average of 1.42 years after treatment for their initial episode, and 3 patients developed a third episode an average of 3.15 years after that. Causes of subsequent episodes of raised ICP often differed from previous episodes and required different management. Patients who were $<1$ year old when the first episode was diagnosed were at increased risk of recurrence.

CONCLUSIONS Although the incidence of raised ICP in CS is high, it did not occur in nearly $40 \%$ of children during the course of this study. The several possible causes of CS require different management and may vary from episode to episode. The authors recommend an expectant policy toward these children with careful clinical, ophthalmological, respiratory, and radiological monitoring for raised ICP, reserving intervention for when it has been detected and the appropriate treatment can be initiated.

http://thejns.org/doi/abs/10.3171/2015.6.PEDS15177

KEY WORDS Crouzon syndrome; raised intracranial pressure; craniofacial

$\mathrm{C}$ ROUZON syndrome (CS) is a congenital autosomal dominant disorder with an incidence of 1 in 25,000 births, ${ }^{22}$ first described by Crouzon in $1912 .{ }^{8}$ It affects skull and facial growth and its most consistent clinical features include craniosynostosis, involving in particular the coronal sutures (but often pan-synostosis) and Class III malocclusion due to maxillary hypoplasia. ${ }^{22}$ A combination of these features results in exorbitism due to lack of depth of the orbits. ${ }^{22}$ Subtle anomalies of other structures, including the limbs ${ }^{5}$ and vertebrae, ${ }^{4}$ are also well recognized. ${ }^{3}$

The incidence of raised intracranial pressure (ICP) in untreated cases of CS has been reported as $62.5 \% .{ }^{22}$ Possible consequences include visual loss that can extend to blindness ${ }^{6,15,18,30}$ as well as impaired neurocognitive development. ${ }^{23}$ The causes of raised ICP are multiple. Although once attributed to craniocerebral disproportion (CCD), ${ }^{23}$ this has largely been discounted since the measurement of intracranial volume became available ${ }^{10,11,27}$ (except for patients under the age of 1 year $^{28}$ and those whose skull growth rate declines following vault expansion surgery ${ }^{29}$ ) in favor of (often in combination) hydrocephalus, ${ }^{7}$ airway obstruction,,$^{13}$ and intracranial venous hypertension $(\mathrm{VH}) .^{14,31}$

ABBREVIATIONS CCD = craniocerebral disproportion; $C S=$ Crouzon syndrome; $E D T=$ electrodiagnostic test; FFA = frontofacial advance; FOA = frontoorbital advance; $\mathrm{ICP}=$ intracranial pressure; ICPM = ICP monitoring; ICV = intracranial volume; $\mathrm{VH}$ = venous hypertension; VP = ventriculoperitoneal.

SUBMITTED March 26, 2015. ACCEPTED June 18, 2015.

INCLUDE WHEN CITING Published online November 27, 2015; DOI: 10.3171/2015.6.PEDS15177. 
Because not all patients with CS (and other craniosynostosis-associated syndromes) develop raised ICP and because not all who do require cranial surgery for its management, the practice in our center has been to monitor children closely for evidence of elevated ICP and treat its particular cause(s) only after it has been detected. This practice is in contrast to some craniofacial units, in which early prophylactic surgery is advocated (once a frontoorbital advance [FOA]; more recently, a posterior vault expansion $^{9,12}$ ) for patients at the time of their initial presentation, even if their ICP is not demonstrably elevated.

In a previous report from our unit, we analyzed the incidence, causes, and subsequent history of raised ICP in patients with Apert syndrome ${ }^{19}$ who were treated expectantly, as described above. The aim of this study was to examine, in a similar fashion, a series of children with CS managed over much the same time period.

\section{Methods}

We conducted a retrospective review of the clinical records of patients with CS who were first seen at the Great Ormond Street Hospital for Children between July 1985 and May 2009. The diagnosis was made on clinical grounds supported by specialist geneticist opinion.

To be enrolled, children had to have had no previous cranial vault (or other potentially ICP-lowering) surgery at presentation and be $\geq 5$ years old at the time of their latest review.

Demographic data collected included age at first referral; sex; age at first diagnosis of raised ICP; its etiology; its management; whether it recurred; and in cases where it did recur, age at recurrence, etiology, and subsequent management.

At first referral to our unit, all children underwent a multidisciplinary assessment that included ophthalmic examination (including funduscopy with retinal photography and electrodiagnostic tests [EDTs]), polygraphic cardiorespiratory sleep studies (to detect obstructive and/or central sleep apnea), and CT scanning. These assessments (adjusted as necessary according to clinical circumstances) were repeated at 3, 6, 12, and 18 months of age, and then at 3,4, 6 , and 10 years of age. Further details are contained in our previous study of children with Apert syndrome. ${ }^{19}$

Raised ICP was diagnosed clinically (singly or in combination) by the presence of such "first-line" indicators as papilledema and/or a tense and bulging fontanelle in infants (or craniectomy defects from previous surgery in older children); scan evidence of progressive ventriculomegaly; and deteriorating EDTs S6,17,32 $^{16}$ supported by radiological evidence (as described by Tuite et al. ${ }^{35}$ ). In the early part of the study period, invasive ICP monitoring (ICPM) was routinely performed at presentation. However, since the late $1990 \mathrm{~s}$, we have increasingly relied on deterioration in EDTs (in particular, pattern reversal visual evoked potentials) as an indirect measure of raised ICP, ${ }^{16,17,33}$ reserving ICPM for quantitative confirmation when required. When performed, ICPM was continued for 48 hours and results were categorized according to the range proposed by Renier et al..$^{23}(<10 \mathrm{~mm} \mathrm{Hg}$, normal; $10-15 \mathrm{~mm} \mathrm{Hg}$, borderline; and $>15 \mathrm{~mm} \mathrm{Hg}$, raised), with the addition of plateau waves if they more than doubled the baseline measurement and were sustained for $\geq 20$ minutes. ${ }^{33}$

Low sensitivity and specificity symptoms in older children, such as headache and changes in school performance, were not considered sufficient for a diagnosis of raised ICP without supporting evidence from among the categories listed above.

Although raised ICP occurring in children with complex/syndromic forms of craniosynostosis may have input from more than 1 cause, for the purposes of this study, we determined the main contributor to each episode of raised ICP according to the primary procedure chosen for its management.

These contributors were defined as follows. 1) Hydrocephalus-progressive ventricular enlargement accompanied by other (clinical and/or radiological) evidence of raised ICP. 2) Airway obstruction - a sufficient number of (nocturnal) arousals and drops in saturation plus clinical evidence of sufficient airway obstruction to justify intervention. ${ }^{19}$ 3) $\mathrm{CCD} / \mathrm{VH}$-raised ICP in the absence of either hydrocephalus or airway obstruction sufficient to justify intervention ${ }^{14}$ (see Discussion).

Children in whom raised ICP was not detected continued with multidisciplinary monitoring at regular intervals as described above.

\section{Results}

The study comprised 49 children (24 girls and 25 boys) with a clinical diagnosis of CS who were referred to our unit between July 1985 and May 2009. None were recorded as having acanthosis nigricans. The 49 children were divided into 3 groups, according to their ICP history: Group A, no episode of raised ICP; Group B, a single episode of raised ICP; and Group C, > 1 episode of raised ICP.

The patient's age at first presentation to our unit, the length of follow-up, and the incidence of raised ICP for each group is given in Table 1. In summary, 19 of 49 children (approximately 40\%) did not develop raised ICP while under regular multidisciplinary observation (lasting between 7 years, 2 months and 8 years, 8 months) in our unit. Of 30 children who did develop raised ICP (Groups $\mathrm{B}$ and $\mathrm{C}$ ), the diagnosis was made at $<1$ year old in 16 children and was supported by sufficient tension and bulging of their fontanelles to justify intervention aimed at whatever was considered to be the major contributor. The ages of the remaining 14 children ranged from 1 year, 2 months to 6 years, 4 months (with precise age information missing for 2 older children). In 12 children, the diagnosis (in the absence of a still open fontanelle and/or bulging craniectomy defects from earlier surgery) was made due to ophthalmic concerns (i.e., papilledema and/or deteriorating EDTs). In the 2 children diagnosed with hydrocephalus at $>1$ year old ( 1 year, 7 months and 1 year, 8 months, respectively), their progressive ventricular enlargement was considered sufficiently severe to justify intervention.

Sixteen children suffered a single episode, whereas 14 (approximately 30\%) patients suffered multiple episodes. A first episode detected at $\leq 1$ year of age (16 of 30) carried a statistically significant chance of subsequent rises in ICP occurring (11 of 14 in Groups B and C, p < 0.05). 
TABLE 1. Age at first presentation, length of follow-up, and incidence of raised ICP in 49 patients with CS

\begin{tabular}{|c|c|c|c|}
\hline Variable & Group A & Group B & Group C \\
\hline No. of pts (\%) & $19(38.8)$ & $16(32.6)$ & $14(28.5)$ \\
\hline \multicolumn{4}{|l|}{ Age when first seen } \\
\hline Range & 4 mos to $10 \mathrm{yrs}$ & $1 \mathrm{mo}$ to 6 yrs & 2 mos to 3 yrs \\
\hline Mean & 3 yrs & $1 \mathrm{yr}, 6 \mathrm{mos}$ & $7 \mathrm{mos}$ \\
\hline \multicolumn{4}{|l|}{ Length of follow-up } \\
\hline Range & $1 \mathrm{mo}$ to $13 \mathrm{yrs}$ & $2 \mathrm{mos}$ to $17 \mathrm{yrs}, 11 \mathrm{mos}$ & $3 \mathrm{yrs}, 7 \mathrm{mos}$ to $19 \mathrm{yrs}, 8 \mathrm{mos}$ \\
\hline Mean & $7 \mathrm{yrs}, 2 \mathrm{mos}$ & $7 \mathrm{yrs}, 9 \mathrm{mos}$ & $8 \mathrm{yrs}, 8 \mathrm{mos}$ \\
\hline Age at first episode & NA & & \\
\hline Range & & 4 mos to 6 yrs, 4 mos & 4 mos to 4 yrs \\
\hline Mean & & $2 \mathrm{yrs}, 2 \mathrm{mos}$ & $1 \mathrm{yr}, 6 \mathrm{mos}$ \\
\hline No. of pts $w /$ first episode at $\leq 1 \mathrm{yr}$ old & NA & 3 & 11 \\
\hline
\end{tabular}

NA = not applicable; pts = patients.

No child under the age of 1 year developed raised ICP due primarily to airway obstruction (see Discussion).

\section{Causes and Management of Raised ICP \\ Initial Episodes of Raised ICP (whether repeated or not)}

Causes. The cause of an initial episode of raised ICP (as reflected by its management) in the 30 children who developed it was hydrocephalus in 8 patients and airway obstruction in 3 . In the remaining 19 children, the presumptive diagnosis was $\mathrm{CCD} / \mathrm{VH}$. The average ages when each of these causes was diagnosed were 1) $\mathrm{CCD} / \mathrm{VH}, 23$ months; 2) airway obstruction, 18 months; and 3) hydrocephalus, 8 months.

Management. $\mathrm{CCD} / \mathrm{VH}$ was treated with a posterior or posterolateral vault expansion in 16 cases and by FOA in 3 (ages 1 year; 4 years, 11 months; and 6 years, 4 months. Hydrocephalus was treated by a ventriculoperitoneal (VP) shunt in all 8 patients. Airway obstruction was managed as required by nasopharyngeal airway/prong insertion, ${ }^{1,20}$ continuous positive airway pressure, and/or adenotonsillectomy. ${ }^{2}$

\section{Subsequent Episodes of Raised ICP}

Table 2 shows treatment methods used for subsequent episodes of raised ICP and the time interval between each episode.

A Second Episode. A second episode of raised ICP occurred in 14 of 30 patients who developed at least 1 episode. It was due (excluding shunt blockage) to $\mathrm{CCD} / \mathrm{VH}$ alone in 6 patients; a combination of $\mathrm{CCD} / \mathrm{VH}$ and airway obstruction (for which a monobloc frontofacial advance [FFA] was performed after a preliminary tracheostomy) in 2; and hydrocephalus in 6.

A second episode occurred in 6 of 8 children in whom their first episode was due to hydrocephalus (an average of 1 year, 7 months later) and in 8 of 19 children originally diagnosed with $\mathrm{CCD} / \mathrm{VH}$ (an average of 1 year, 1 month later).

None of the 3 patients in whom airway obstruction was the prime contributor to their original diagnosis of raised ICP suffered a recurrence, although it was responsible for a second episode in 1 child (whose original episode was due to $\mathrm{CCD} / \mathrm{VH})$.
Second Recurrence. A third episode of raised ICP occurred in 3 patients, an average of 3 years, 2 months after they had been treated for their second episode. The management of their 3 episodes can be summarized as follows: Case 1-VP shunt, then vault expansion, and then further vault expansion; Case 6-vault expansion, then monobloc FFA, and then further vault expansion; and Case 13-vault expansion, then endoscopic third ventriculostomy, and then monobloc FFA.

\section{Discussion}

In a recently published Dutch study, ${ }^{29}$ children with syndromic/complex forms of craniosynostosis were routinely "scheduled for vault expansion within the first year, or shortly after referral if the child was older at first presentation." However, of 62 patients (11 of them with CS), $49(79 \%)$ did not have raised ICP at the time of their operation.

Our study shows that close to half (approximately 40\%) of children enrolled in a multidisciplinary craniofacial unit with a clinical diagnosis of CS, who were followed for 7-8 years, did not develop raised ICP. This mirrors a previous report of ICP-monitored raised ICP in $62.5 \%$ of patients with $\mathrm{CS}^{22}$ (although those authors' own reference suggests the number actually monitored may have been as low as 9 patients $^{21}$ ). Of patients in our study who did develop raised ICP, the most common causes were, not unexpectedly, hydrocephalus and $\mathrm{CCD} / \mathrm{VH}$. This differs a little from our findings in a study of children with Apert syndrome, ${ }^{19}$ in whom a higher proportion (20 of 24 patients [83\%]) developed at least 1 episode of raised ICP. In that study, the most frequent cause was also CCD/VH and, as in the present study, approximately one-third (7 of 20 patients) subsequently developed a further episode.

It is possible that we may have underestimated the prevalence of raised ICP in CS, by "inadvertently" preventing it by other procedures. Although patients were included in the study only if they had "No previous cranial vault (or other potentially ICP-lowering) surgery" (e.g., an FOA performed for ocular protection or cosmesis), some younger children (and more severely affected ones in particular) had received earlier attention to an obstructed airway (receiving a nasopharyngeal prong ${ }^{20}$ or even tra- 
TABLE 2. Management of second and third episodes of raised ICP (Group C) and time interval between episodes

\begin{tabular}{|c|c|c|c|c|c|}
\hline Case No. & First Episode Treatment (age) & Time Interval & Second Episode Treatment (age) & Time Interval & Third Episode Treatment (age) \\
\hline 1 & VP shunt (4 mos) & $1 \mathrm{yr}$ & VE (1 yr, 4 mos) & $5 \mathrm{yrs}, 2 \mathrm{mos}$ & VE (6 yrs, 6 mos) \\
\hline 2 & VP shunt (4 mos) & $1 \mathrm{yr}, 3 \mathrm{mos}$ & VE (1 yr, 7 mos) & NA & NA \\
\hline 3 & VP shunt (4 mos) & $1 \mathrm{yr}, 8 \mathrm{mos}$ & VE (2 yrs) & NA & NA \\
\hline 4 & VP shunt (4 mos) & $5 \mathrm{mos}$ & Monobloc FFA (9 mos) & NA & NA \\
\hline 5 & VE (4 mos) & $6 \mathrm{mos}$ & VE (10 mos) & NA & NA \\
\hline 6 & VE (4 mos) & $1 \mathrm{yr}, 2 \mathrm{mos}$ & Monobloc FFA (1 yr, 6 mos) & $2 \mathrm{yrs}, 11 \mathrm{mos}$ & VE (4 yrs, 5 mos) \\
\hline 7 & VE (5 mos) & $1 \mathrm{yr}, 7 \mathrm{mos}$ & VP shunt (2 yrs) & NA & NA \\
\hline 8 & VE (8 mos) & 10 mos & VE (1 yr, 6 mos) & NA & NA \\
\hline 9 & VE (7 mos) & 10 mos & VE (1 yr, 5 mos) & NA & NA \\
\hline 10 & VP shunt (9 mos) & $3 \mathrm{yrs}, 5 \mathrm{mos}$ & VE (4 yrs, 2 mos) & NA & NA \\
\hline 11 & VE (1 yr) & $2 \mathrm{yrs}, 1 \mathrm{mo}$ & VE (3 yrs, $1 \mathrm{mo})$ & NA & NA \\
\hline 12 & VP shunt (1 yr, 8 mos) & $4 \mathrm{yrs}, 10 \mathrm{mos}$ & VE (6 yrs, 6 mos) & NA & NA \\
\hline 13 & VE (2 yrs, 6 mos) & $1 \mathrm{yr}, 8 \mathrm{mos}$ & ETV (4 yrs, 2 mos) & $1 \mathrm{yr}, 6 \mathrm{mos}$ & Monobloc FFA (5 yrs, 8 mos) \\
\hline 14 & VE (4 yrs) & $2 \mathrm{mos}$ & Airway intervention (4 yrs, 2 mos) & NA & NA \\
\hline
\end{tabular}

ETV = endovascular third ventriculostomy; NA = not applicable; VE = vault expansion.

cheostomy), whereas older children may have undergone adenotonsillectomy. All of these procedures could have a potential effect on ICP. With regard to the younger children, both the mean ages of those in Groups B and C at a first episode of raised ICP (1 year, 6 months and 7 months, respectively), and the fact that no child under the age of 1 year developed raised ICP due to airway obstruction, suggest that whatever their previous method of airway management had been (if any), their risk of developing raised ICP had not been abolished by it. Adenotonsillectomy may have averted raised ICP in older children. However, if the higher mean age at presentation ( 3 years) among children never experiencing a rise in ICP is taken as an indication that they were phenotypically less affected (see also below) and therefore less likely to develop raised ICP, the number so affected is likely to be small.

We therefore contend that although airway management, with its recognized effects on ICP in children with complex forms of craniosynostosis, may have averted a rise sufficient to require treatment in some children, the numbers affected in this way will be small.

It is also possible, given the number of patients (19 of 49) who did not (according to our criteria) develop raised ICP, that the diagnosis could have either been missed or diagnosed earlier than it actually was. We consider this unlikely, given the intensity, regularity, and length of follow-up of the multidisciplinary monitoring to which these children were subjected.

When presented with a child with a syndromic-associated/complex form of craniosynostosis such as CS, our previous policy was, similar to the unit referred to above, ${ }^{29}$ to recommend some form of vault expansion surgery (in early days, this was an FOA), even in the absence of clinical evidence of raised ICP. Not only, according to the theory, would this forestall any subsequent rise in ICP, but it would also have cosmetic benefits. However, when our early policy of ICPM for all such children revealed the numbers in whom it was not raised (and who did not de- velop it later), we changed to a more expectant strategy. This new policy included regular clinical (in particular ophthalmic) monitoring, with intervention reserved for those in whom raised ICP was confirmed (with or without ICP monitoring). Although this policy was not formalized until the mid-1990s, we were effectively adhering to it before then by restricting vault expansion to those in whom raised ICP was either too clinically obvious to ignore (e.g., tense, bulging fontanelles in infants) or those early patients whose ICP had been monitored.

Such expansion surgery remains, however, an important component of the craniofacial surgeon's armory when treating a child with clinically (or otherwise) confirmed raised ICP when the primary cause is $\mathrm{CCD} / \mathrm{VH}$. These days, however, a posterior approach (usually effected using springs technology $y^{9}$ ) is preferred to an FOA to avoid the frontal bone and soft-tissue dissection that can render subsequent frontofacial (monobloc) surgery (with or without distraction) more complicated.

It could be argued that our patients will miss out on any cosmetic benefits they might derive from an early FOA. Our experience, however, is that although an early frontal reconstruction may be of lasting cosmetic benefit for children with the less functionally severe craniosynostosisassociated syndromes (e.g., Saethre-Chotzen and FGFR3/ Muenke), the subsequent relapse of any such gains from early intervention in children with CS has led us to "preserve" the frontal region until more lasting results can be achieved (e.g., by frontofacial/monobloc surgery). In our opinion, this policy has led to improvements in the eventual cosmetic outcome.

Therefore, it remains our contention that the results reported here are strongly supportive of an "expectant" policy for the management of raised ICP in CS and that, as a consequence, 19 of 49 children with that diagnosis were spared the "routine" cranial expansion surgery they might previously have undergone. 


\section{Diagnosis of CS}

It is appreciated that despite the explosion of knowledge of the genetics of syndromic craniosynostosis that occurred during the period of this study, the many overlaps between the mutations responsible for CS and/or Pfeiffer syndrome $^{24,26}$ (plus the discoveries of ERF $F^{36}$ and $T C F 12^{36}$ mutations responsible for "Crouzon-like" phenotypes) means that there is no single mutation that can stand as a molecular genetic definition of CS. For the purposes of this study, we have therefore defined CS on the basis of the patient's phenotypic appearance. This is usually a combination of bicoronal synostosis, maxillary hypoplasia, and a characteristic "beaked" nose in the absence of digital abnormalities that would otherwise have (traditionally) suggested a diagnosis of Pfeiffer syndrome.

We appreciate, however, that the absence of acanthosis nigricans in the clinical records may underestimate the incidence of a syndrome that was only starting to become recognized clinically and genetically ${ }^{37}$ during our study period.

\section{The Diagnosis and Management of Raised ICP}

Raised ICP is an important complication of the syndromic forms of craniosynostosis. Its early detection and treatment may prevent harm both to vision and neurocognitive development. Detection of raised ICP often depends upon an accumulation of evidence from several sources, including clinical (particularly ophthalmic), radiological, and/or that derived from ICPM. Despite their own uncertainty over the normal range for childhood ICP ("The definition of 'normal' and 'abnormal' ICP recordings in children raises an initial problem" ${ }^{23}$ ), during the period of the present study, we accepted the classification of ICP suggested by Renier et al. in $1982 .{ }^{23}$

We have not, however, accepted such low sensitivity and specificity symptoms as headache and changes in school performance as sufficient indicators of raised ICP in the context of craniosynostosis to justify intervention, unless accompanied by at least 1 of those indicators listed in Methods.

For the purposes of this study, we equated the diagnosis of raised ICP with sufficient concern (i.e., clinical, ophthalmic, and radiological) to justify intervention specifically aimed at its reduction. We appreciate that this definition could be criticized as too subjective. However, we would argue that, given uncertainty over the normal childhood range of ICP, ${ }^{23}$ the potentially deleterious effects on vision and cerebral function of (singly or in combination) papilledema, hydrocephalus, an infant's obviously tense and bulging fontanelle (or craniectomy defects in the older child), and a severely obstructed airway are sufficiently well-recognized danger signals to support this approach.

When faced with a child with overtly raised ICP (e.g., tense and bulging fontanelles/craniectomy defects) and moderately expanded ventricles, it can be difficult to decide whether to proceed to vault expansion or some form of CSF diversion. Our experience has been that vault expansion in this situation may (particularly in younger children) lead to rapid acceleration of their ventriculomegaly. ${ }^{34}$ Our policy has been to use both the degree and speed of progression of ventriculomegaly as indications for CSF diversion in the first instance, while recognizing that the child may still require vault expansion at a later date.

\section{Craniocerebral Disproportion/Venous Hypertension}

Until the early 1990s, it was widely assumed that failure of the skull to grow (CCD) was, in the absence of hydrocephalus, the main cause of raised ICP in CS and other craniosynostosis-associated syndromes. ${ }^{23}$ This assumption has been modified because 1) actual measurements of intracranial volume (ICV) have shown it is probably only of relevance for children who are $<1$ year old $10,27,28$ and/ or those whose skull growth rate declines following vault expansion surgery; ${ }^{29}$ and 2) the role of VH has become appreciated, ${ }^{14,25,31}$ particularly when associated with airway obstruction. ${ }^{13}$ Although some of the children in this report were among those with previously ICPM-confirmed raised ICP in whom digital subtraction angiography had demonstrated obstructed intracranial venous drainage, ${ }^{31}$ the diagnosis of $\mathrm{VH}$ was largely one of exclusion supported by clinical and scan evidence of prominent venous collateral channels. We have not measured ICV in the children in this study because those who developed raised ICP at $\leq 1$ year old (14 of 30 patients) are also those most likely to have had reduced ICV, CCD, and VH, which have been combined for the purposes of this report.

\section{Recurrence of Raised ICP in CS}

Of 30 children who developed raised ICP, approximately half (14) of them developed a second episode after initially successful management; of those, 3 children went on to suffer a third episode. Risk factors for developing raised ICP at all were a younger age at initial referral (the mean ages were 1 year, 6 months and 7 months for Groups $\mathrm{B}$ and C, respectively, compared with 3 years for Group A) and, in particular, referral at the age of 1 year or younger (16 of 30). This presumably reflects the variable severity of the phenotype, whereas the incidence of recurrence (with its often different causes) acts a reminder that "craniosynostosis" in its complex/syndromic forms is a dynamic rather than static process.

Fortunately, susceptibility to the development of raised ICP appears to be time limited. Our experience of children with CS mirrors that of our study of Apert syndrome, ${ }^{19}$ in which a first (or subsequent) rise in ICP was unlikely after the age of 7 years. For this reason, we strongly recommend that monitoring tailored to the detection of raised ICP be continued until at least the age of 8 years.

Finally, it could be argued that (particularly in the severely affected infant) ICP and airway obstruction are so intermingled that to concentrate on ICP alone provides a distorted view of the problems posed by CS. We submit, however, that knowledge of not only the incidence of raised ICP but also the importance of its various contributors (together with the likelihood of recurrence following apparently successful treatment) is of particular value to those tasked with the management of this complex condition.

\section{Conclusions}

A significant proportion (40\%) of children with a clini- 
$\mathrm{cal} /$ phenotypic diagnosis of CS did not develop raised ICP during a follow-up period of 7-8 years. Of those who did, approximately half (14 of 30) faced 1 or 2 further episodes. Children at particular risk were those whose first episode occurred at or before the age of 1 year. The most likely cause for a first episode was $\mathrm{CCD} / \mathrm{VH}$, followed by hydrocephalus and airway obstruction. Causes of subsequent episodes may differ, however, and therefore may require different management.

These findings do not support a policy of prophylactic vault expansion in the absence of confirmatory evidence of raised ICP in children with CS (and by implication other forms of syndromic craniosynostosis). However, even if it has not been previously diagnosed, regular clinical and ophthalmic monitoring aimed at its detection should be continued until at least the age of 8 years.

\section{References}

1. Ahmed J, Marucci D, Cochrane L, Heywood RL, Wyatt ME, Leighton SE: The role of the nasopharyngeal airway for obstructive sleep apnea in syndromic craniosynostosis. J Craniofac Surg 19:659-663, 2008

2. Amonoo-Kuofi K, Phillips SP, Randhawa PS, Lane R, Wyatt ME, Leighton SE: Adenotonsillectomy for sleep-disordered breathing in children with syndromic craniosynostosis. J Craniofac Surg 20:1978-1980, 2009

3. Anderson PJ: Crouzon syndrome: anomalies not limited to the skull and the face. J Craniomaxillofac Surg 25:356-357, 1997

4. Anderson PJ, Hall C, Evans RD, Harkness WJ, Hayward RD, Jones BM: The cervical spine in Crouzon syndrome. Spine (Phila Pa 1976) 22:402-405, 1997

5. Anderson PJ, Hall CM, Evans RD, Jones BM, Hayward RD: Hand anomalies in Crouzon syndrome. Skeletal Radiol 26:113-115, 1997

6. Bartels MC, Vaandrager JM, de Jong THR, Simonsz HJ: Visual loss in syndromic craniosynostosis with papilledema but without other symptoms of intracranial hypertension. J Craniofac Surg 15:1019-1022, 2004

7. Collmann H, Sörensen N, Krauss J: Hydrocephalus in craniosynostosis: a review. Childs Nerv Syst 21:902-912, 2005

8. Crouzon O: Dysostose craniofaciale héréditaire. Bull Soc Med Hôp (Paris) 33:545-555, 1912

9. de Jong T, van Veelen MLC, Mathijssen IMJ: Spring-assisted posterior vault expansion in multisuture craniosynostosis. Childs Nerv Syst 29:815-820, 2013

10. Fok H, Jones BM, Gault DG, Andar U, Hayward R: Relationship between intracranial pressure and intracranial volume in craniosynostosis. Br J Plast Surg 45:394-397, 1992

11. Gault DT, Renier D, Marchac D, Ackland FM, Jones BM: Intracranial volume in children with craniosynostosis. J Craniofac Surg 1:1-3, 1990

12. Goldstein JA, Paliga JT, Wink JD, Low DW, Bartlett SP, Taylor JA: A craniometric analysis of posterior cranial vault distraction osteogenesis. Plast Reconstr Surg 131:1367-1375, 2013

13. Gonsalez S, Hayward R, Jones B, Lane R: Upper airway obstruction and raised intracranial pressure in children with craniosynostosis. Eur Respir J 10:367-375, 1997

14. Hayward R: Venous hypertension and craniosynostosis. Childs Nerv Syst 21:880-888, 2005

15. Hertle RW, Quinn GE, Minguini N, Katowitz JA: Visual loss in patients with craniofacial synostosis. J Pediatr Ophthalmol Strabismus 28:344-349, 1991

16. Liasis A, Nischal KK, Walters B, Thompson D, Hardy S,
Towell A, et al: Monitoring visual function in children with syndromic craniosynostosis: a comparison of 3 methods. Arch Ophthalmol 124:1119-1126, 2006

17. Liasis A, Thompson DA, Hayward R, Nischal KK: Sustained raised intracranial pressure implicated only by pattern reversal visual evoked potentials after cranial vault expansion surgery. Pediatr Neurosurg 39:75-80, 2003

18. Liasis A, Walters B, Thompson D, Smith K, Hayward R, Nischal KK: Visual field loss in children with craniosynostosis. Childs Nerv Syst 27:1289-1296, 2011

19. Marucci DD, Dunaway DJ, Jones BM, Hayward RD: Raised intracranial pressure in Apert syndrome. Plast Reconstr Surg 122:1162-1170, 2008

20. Randhawa PS, Ahmed J, Nouraei SR, Wyatt ME: Impact of long-term nasopharyngeal airway on health-related quality of life of children with obstructive sleep apnea caused by syndromic craniosynostosis. J Craniofac Surg 22:125-128, 2011

21. Renier D: Intracranial pressure in craniosynostosis: pre- and postoperative recordings. Correlation with function results, in Persing JA, Edgerton MT, Jane JA (eds): Scientific Foundation and Surgical Treatment of Craniosynostosis. Baltimore: Williams \& Wilkins, 1989, pp 263-274

22. Renier D, Lajeunie E, Arnaud E, Marchac D: Management of craniosynostoses. Childs Nerv Syst 16:645-658, 2000

23. Renier D, Sainte-Rose C, Marchac D, Hirsch JF: Intracranial pressure in craniostenosis. J Neurosurg 57:370-377, 1982

24. Rutland P, Pulleyn LJ, Reardon W, Baraitser M, Hayward R, Jones B, et al: Identical mutations in the FGFR2 gene cause both Pfeiffer and Crouzon syndrome phenotypes. Nat Genet 9:173-176, 1995

25. Sainte-Rose C, LaCombe J, Pierre-Kahn A, Renier D, Hirsch JF: Intracranial venous sinus hypertension: cause or consequence of hydrocephalus in infants? J Neurosurg 60:727736,1984

26. Schell U, Hehr A, Feldman GJ, Robin NH, Zackai EH de D-SC, de Die-Smulders C, et al: Mutations in FGFR1 and FGFR2 cause familial and sporadic Pfeiffer syndrome. Hum Mol Genet 4:323-328, 1995

27. Sgouros S: Skull vault growth in craniosynostosis. Childs Nerv Syst 21:861-870, 2005

28. Sgouros S, Hockley AD, Goldin JH, Wake MJ, Natarajan K: Intracranial volume change in craniosynostosis. J Neurosurg 91:617-625, 1999

29. Spruijt B, Joosten KFM, Driessen C, Rizopoulos D, Naus NC, van der Schroeff MP, et al: Algorithm for the management of intracranial hypertension in children with syndromic craniosynostosis. Plast Reconstr Surg 136:331-340, 2015

30. Tay T, Martin F, Rowe N, Johnson K, Poole M, Tan K, et al: Prevalence and causes of visual impairment in craniosynostotic syndromes. Clin Experiment Ophthalmol 34:434440, 2006

31. Taylor WJ, Hayward RD, Lasjaunias P, Britto JA, Thompson DN, Jones BM, et al: Enigma of raised intracranial pressure in patients with complex craniosynostosis: the role of abnormal intracranial venous drainage. J Neurosurg 94:377-385, 2001

32. Thompson DA, Liasis A, Hardy S, Hagan R, Hayward RD, Evans RD, et al: Prevalence of abnormal pattern reversal visual evoked potentials in craniosynostosis. Plast Reconstr Surg 118:184-192, 2006

33. Thompson DN, Harkness W, Jones B, Gonsalez S, Andar U, Hayward R: Subdural intracranial pressure monitoring in craniosynostosis: its role in surgical management. Childs Nerv Syst 11:269-275, 1995

34. Thompson DNP, Jones BM, Harkness W, Gonsalez S, Hayward RD: Consequences of cranial vault expansion surgery for craniosynostosis. Pediatr Neurosurg 26:296-303, 1997

35. Tuite GF, Evanson J, Chong WK, Thompson DNP, Harkness 
WF, Jones BM, et al: The beaten copper cranium: a correlation between intracranial pressure, cranial radiographs, and computed tomographic scans in children with craniosynostosis. Neurosurgery 39:691-699, 1996

36. Twigg SR, Vorgia E, McGowan SJ, Peraki I, Fenwick AL, Sharma VP, et al: Reduced dosage of ERF causes complex craniosynostosis in humans and mice and links ERK1/2 signaling to regulation of osteogenesis. Nat Genet 45:308-313, 2013

37. Vajo Z, Francomano CA, Wilkin DJ: The molecular and genetic basis of fibroblast growth factor receptor 3 disorders: the achondroplasia family of skeletal dysplasias, Muenke craniosynostosis, and Crouzon syndrome with Acanthosis nigricans. Endocr Rev 21:23-39, 2000

\section{Disclosures}

The authors report no conflict of interest concerning the materi- als or methods used in this study or the findings specified in this paper.

\section{Author Contributions}

Conception and design: Hayward, Dunaway. Acquisition of data: Abu-Sittah. Analysis and interpretation of data: Abu-Sittah. Drafting the article: Hayward, Abu-Sittah. Critically revising the article: Jeelani, Dunaway. Reviewed submitted version of manuscript: all authors. Approved the final version of the manuscript on behalf of all authors: Hayward.

\section{Correspondence}

Richard Hayward, Department of Neurosurgery, Great Ormond Street Hospital for Children NHS Trust Foundation, Great Ormond St., London, WC1N 3JH, United Kingdom. email: richard.hayward@gosh.nhs.uk. 